\title{
Correction: Moxley, R.A., et al. Intimate Attachment of Escherichia coli O157:H7 to Urinary Bladder Epithelium in the Gnotobiotic Piglet Model. Microorganisms 2020, 8, 263
}

\author{
Rodney A. Moxley ${ }^{1, *}$, Tom W. Bargar ${ }^{2}$, Stephen D. Kachman ${ }^{3}{ }^{1}$, Diane R. Baker ${ }^{4}$ \\ and David H. Francis ${ }^{4}$ \\ 1 School of Veterinary Medicine and Biomedical Sciences, University of Nebraska-Lincoln, \\ Lincoln, NE 68583-0905, USA \\ 2 Electron Microscopy Core Facility, University of Nebraska Medical Center, Omaha, NE 68198-6395, USA; \\ tbargar@unmc.edu \\ 3 Department of Statistics, University of Nebraska-Lincoln, Lincoln, NE 68583-0963, USA; \\ steve.kachman@unl.edu \\ 4 Department of Veterinary and Biomedical Sciences, South Dakota State University, \\ Brookings, SD 57007, USA; dbaker@itctel.com (D.R.B.); david.francis@sdstate.edu (D.H.F.) \\ * Correspondence: rmoxley1@unl.edu; Tel.: +1-402-472-8460
}

Received: 9 December 2020; Accepted: 10 December 2020; Published: 17 December 2020

The authors wish to make the following corrections to this paper [1]:

On page 2, the sentence that reads, "Hence, EHEC is a rare but established cause of HUS in children and adults." should read, "Hence, EHEC is a rare but established cause of UTI-associated HUS in children and adults." On page 4, the sentence that reads, "As noted previously, 14 of 126 (13.3\%) piglets orally inoculated with EHEC O157:H7 strains developed mild to moderate purulent cystitis within $8 \mathrm{~d}$ PI [25] (Table 1)." should read, "As noted previously, 14 of 105 (13.3\%) piglets orally inoculated with EHEC O157:H7 strains in which the urinary bladder was examined developed mild to moderate purulent cystitis within $8 \mathrm{~d}$ PI [25] (Table 1)".

The authors would like to apologize for any inconvenience caused to the readers by these changes.

Conflicts of Interest: The authors declare no conflict of interest.

\section{Reference}

1. Moxley, R.A.; Bargar, T.W.; Kachman, S.D.; Baker, D.R.; Francis, D.H. Intimate attachment of Escherichia coli O157:H7 to urinary bladder epithelium in the gnotobiotic piglet model. Microorganisms 2020, 8, 263. [CrossRef] [PubMed]

Publisher's Note: MDPI stays neutral with regard to jurisdictional claims in published maps and institutional affiliations.

(C) 2020 by the authors. Licensee MDPI, Basel, Switzerland. This article is an open access article distributed under the terms and conditions of the Creative Commons Attribution (CC BY) license (http://creativecommons.org/licenses/by/4.0/). 